\title{
Simultaneous DMSP, all-sky camera, and IMAGE FUV observations of the brightening arc at a substorm pseudo-breakup
}

\author{
K. Yago ${ }^{1,5}$, K. Shiokawa ${ }^{1}$, K. Yumoto ${ }^{2}$, D. G. Baishev ${ }^{3}$, S. I. Solovyev ${ }^{3}$, and F. J. Rich \\ ${ }^{1}$ Solar-Terrestrial Environment Laboratory, Nagoya University, Toyokawa, Japan \\ ${ }^{2}$ Space Environment Research Center, Kyushu University, Fukuoka, Japan \\ ${ }^{3}$ Yu.G.Shafer Institute of Cosmophysical Research and Aeronomy, Yakutsk, Russia \\ ${ }^{4}$ Air Force Geophysics Laboratory, Hanscom Air Force Base, Massachusetts, U.S.A. \\ ${ }^{5}$ Currently at Konica Minolta, Japan
}

(Received April 22, 2006; Revised August 11, 2006; Accepted August 25, 2006; Online published March 15, 2007)

\begin{abstract}
Auroral particles, field-aligned currents, and plasma convections in the vicinity of the brightening arc at substorm onset are still not well understood, since it is very rare to have conjugate satellite measurements above the brightening arc. In this paper, we investigate the characteristics of auroral particles and fields associated with the brightening arc at a pseudo-onset of substorm on October 31, 2000, using ground all-sky TV images, IMAGE FUV auroral images, and particle, magnetic field, and plasma flow data obtained by the DMSP F12 satellite. The arc brightening at Tixie (66. $0^{\circ}$ MLAT), Russia, occurred at 1004 UT (18.75 MLT) coincident with a coherent Pi 2 pulsation at midlatitudes and with the DMSP crossing above the arc. The brightening arc did not develop on a global scale, indicating that this event is a pseudo auroral breakup, which occurred $\sim 16$ min before the major substorm expansion onset. IMAGE auroral images indicate that the longitude of the brightening center was $\sim 2.5 \mathrm{~h}$ nightside of Tixie. The DMSP data show that the precipitating particles associated with the brightening arc correspond to an electron inverted- $\mathrm{V}$ structure at the equatorward edge of the electron precipitation region. The arc was located in the energetic $(>1 \mathrm{keV})$ ion precipitation region, near the equatorward boundary of the upward region 1 field-aligned current, and at the peak of the sunward convection velocity. These facts indicate that the brightening arc at duskside of the onset local time was located in the inner plasma sheet at the inner edge of the region 1 current source in the sunward convection region.
\end{abstract}

Key words: Substorm, auroral initial brightening, auroral particle, DMSP.

\section{Introduction}

A substorm is a phenomenon that occurs in the magnetosphere-ionosphere coupling system. A fundamental feature of substorms is the auroral intensification. It is well known that the auroral intensification starts near the equatorward boundary of the auroral oval in the midnight sector (Akasofu, 1964). Particle injection, magnetic field dipolarization, and Pi 2 pulsation are observed when the substorm starts. Although various specific signatures are observed in association with substorms, the triggering mechanism these substorms is not yet understood. Tail current disruption and magnetic reconnection are the most popular models. It has been suggested that the tail current disruption region is inside $10 \mathrm{R}_{E}$ (e.g., Lui, 1996), while the reconnection at the near-Earth neutral line occurs 20-30 $\mathrm{R}_{E}$ tailward from the Earth (e.g., Machida et al., 1999; Runov et al., 2003).

To identify the onset region of magnetospheric substorms, auroral particles associated with the initial auroral brightening at substorm onset have been investigated (e.g., Samson et al., 1992; Dubyagin et al., 2003; Mende et al., 2003; Yago et al., 2005; Shiokawa et al., 2005). These

Copyright (c) The Society of Geomagnetism and Earth, Planetary and Space Sciences (SGEPSS); The Seismological Society of Japan; The Volcanological Society of Japan; The Geodetic Society of Japan; The Japanese Society for Planetary Sciences; TERRAPUB. studies show that the brightening arc at substorm onset is located in the region of plasma sheet energetic ion precipitation in the equatorward part of the auroral oval. However, simultaneous observation of an onset arc and satellite particles is very rare. Previous studies of simultaneous measurements focused on the particle features obtained by the satellites.

The large-scale region 1 and 2 field-aligned currents, initially identified by Iijima and Potemra (1978), indicate that the inner and outer part of the magnetosphere drive different field-aligned currents. The relative location of the brightening arc at substorm onset to the current systems has not been well identified, but it may establish some constraints on the substorm onset models described above. Shiokawa et al. (2005) indicated from a sequence event of substorm onsets that the brightening arc is located in the region 1 large-scale field-aligned current in the sunward convection region. Their event occurred during a sequence of substorm brightenings, when previous activity was still going on.

In this study, we investigate the characteristics of auroral particles, field-aligned currents, and plasma convection associated with the brightening arc at a pure isolated pseudosubstorm on October 31, 2000, using ground and satellite auroral images and DMSP F12 satellite data. The event was a pseudo auroral breakup, which did not develop on global a scale. A major substorm expansion onset occurred 


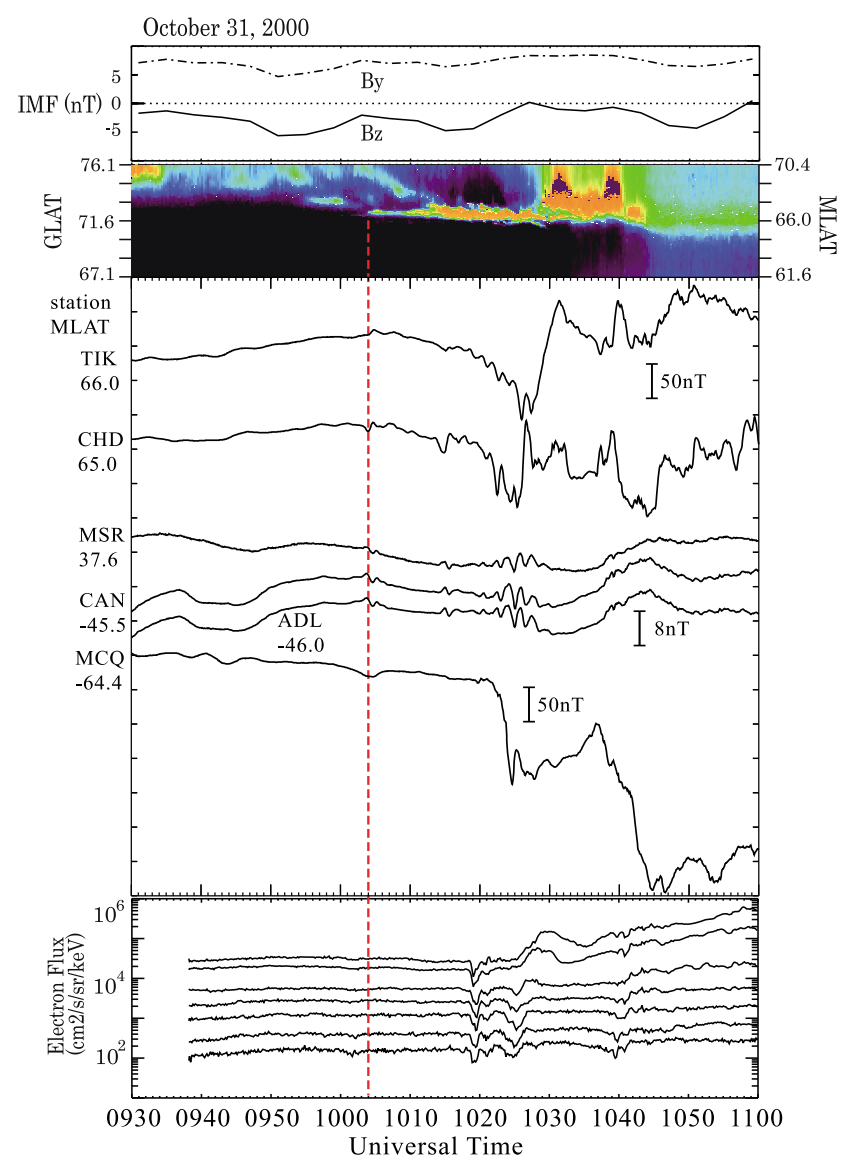

Fig. 1. Interplanetary magnetic field (IMF) variations obtained by the ACE spacecraft, time variations of auroral intensity in a north-south meridian obtained by the all-sky camera at Tixie (TIK), H-component magnetic field variations at TIK, Chokurdakh (CHD), Moshiri (MSR), Canberra (CAN), Adelaide (ADL), and Macquarie Island (MCQ) in the magnetic meridian of TIK, and particle injection measurements made by the LANL 1989-046 spacecraft. The magnetic field data are shown as $50 \mathrm{nT} /$ division for TIK, CHD, and MCQ, and $8 \mathrm{nT} /$ division for MSR, $\mathrm{CAN}$, and ADL.

$\sim 16$ min after the present event. However, Nakamura et al. (1994) and Rostoker (1998) suggested that there are no phenomenological differences between pseudo-substorms and major expansion onsets of substorms. We found that the brightening arc was located at the equatorward edge of the region 1 field-aligned current in the sunward convection region.

\section{Observations}

A panchromatic all-sky TV camera with an image intensifier has been operated at Tixie (TIK, $71.6^{\circ} \mathrm{N}, 128.8^{\circ} \mathrm{E}$, magnetic latitude $\left(\right.$ MLAT) $\left.=66.0^{\circ}\right)$ since 1994. The allsky camera is sensitive to the entire visible wavelength. The time resolution of the camera is $4 \mathrm{~s}$. Details of the all-sky camera are given by Shiokawa et al. (1996). Solovyev et al. (2000) used this camera for comparing auroral forms and Pi 2 pulsations.

We investigated simultaneous observations of substormassociated auroral arcs detected by the all-sky camera at Tixie and auroral particle data obtained by the DMSP satellites in the field-of-view of the Tixie camera from 1997 to 2000. Only five events were available. For three of these,

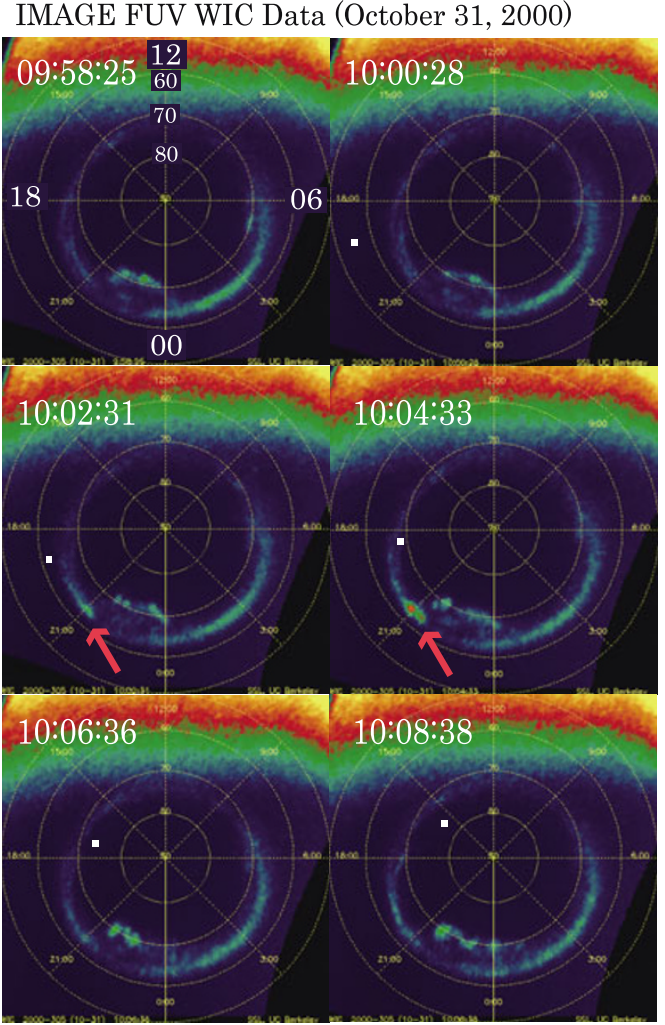

Fig. 2. Auroral images obtained by the IMAGE FUV Wideband Imaging Camera (WIC). The images are in geomagnetic coordinates. Magnetic local time and magnetic latitude are indicated in the 0958:25 UT image. The white squares indicate the footprint of the DMSP F12 spacecraft at an altitude of $120 \mathrm{~km}$.

the time difference between the arc brightening and the DMSP crossing was more than $10 \mathrm{~min}$. The event investigated in this paper is the best one, during which the DMSP crossed the onset arc with a time difference of less than 1 min and the substorm was fairly isolated. The other events, which were reported by Shiokawa et al. (2005), took place when previous substorm activity was still going on.

Figure 1 shows interplanetary magnetic field (IMF) variations obtained by the ACE spacecraft, the auroral intensity variations in a north-south meridian (keogram) obtained by the all-sky camera at TIK, the H-component magnetic field variations at the CPMN stations at TIK, Chokurdakh (CHD), Moshiri (MSR), Canberra (CAN), Adelaide (ADL), and Macquarie Island (MCQ) (Yumoto et al., 2001), and the high energy electron fluxes at energies of $50-315 \mathrm{keV}$ measured by the geosynchronous LANL 1989-046 spacecraft located in the midnight sector, all for the substorm event on October 31, 2000. IMF data is shifted $63 \mathrm{~min}$ by taking the travel time from the ACE spacecraft to the magnetopause into account. The all-sky images are converted to geographical coordinates, assuming an auroral altitude of $120 \mathrm{~km}$. The keogram shows auroral intensity variations at a geographical longitude of TIK $\left(128.8^{\circ} \mathrm{E}\right)$.

In Fig. 1, IMF $B z$ measured by the ACE spacecraft at $\mathrm{X}=219 \mathrm{R}_{E}$ was almost continuously southward $(\sim 0$ to $-5 \mathrm{nT}$ ), and $B y$ was duskward ( $>5 \mathrm{nT}$ ) for 0930-1100 UT. In the keogram, the equatorward boundary of the auroral zone gradually shifts equatorward during the plotted inter- 


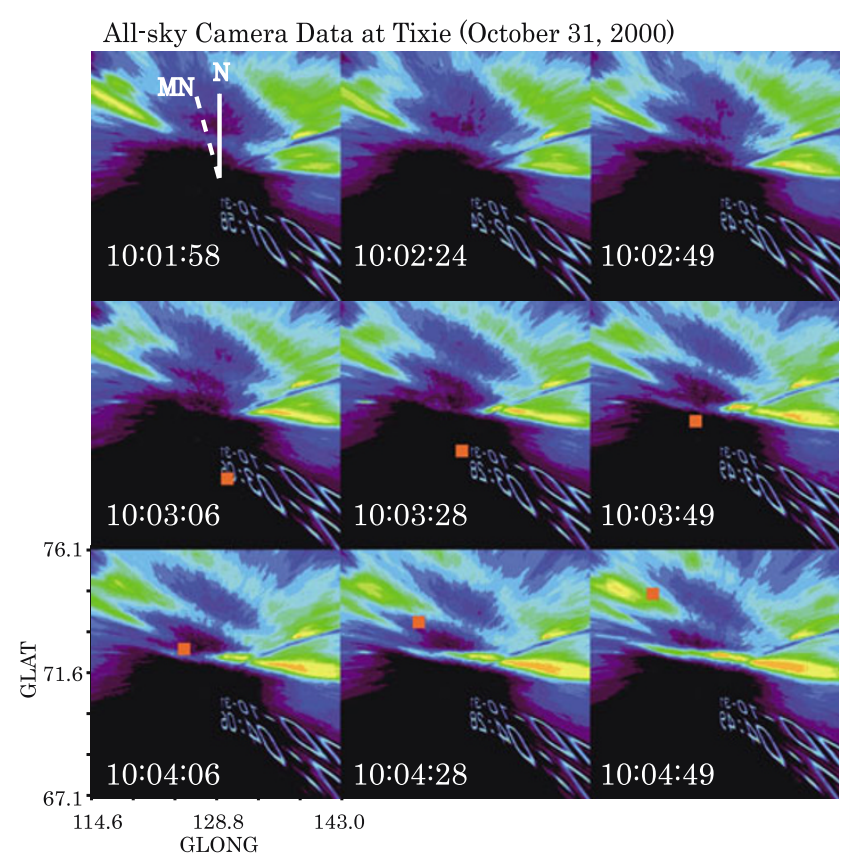

Fig. 3. Auroral images obtained at Tixie. Geographic north (N) and geomagnetic north (MN) are indicated in the 1001:58 UT image. Geographic latitude and longitude are indicated in the 1004:06 UT image. The orange squares indicate the footprint of the DMSP F12 spacecraft at an altitude of $120 \mathrm{~km}$.

val. As indicated by the vertical dashed line, an auroral intensification took place at $\sim 1004$ UT (18.5 MLT at TIK) at the equatorial boundary of the auroral zone at $\sim 66^{\circ} \mathrm{MLAT}$ $\left(\sim 72^{\circ}\right.$ GLAT). The DMSP F12 satellite crossed the arc at this time, as shown later. An equatorward-drifting aurora was simultaneously observed poleward of the brightening arc. However, auroral expansion was not observed in the keogram. Small magnetic field variations were seen in the high-latitude magnetograms at TIK, CHD, and MCQ at this time. Pi 2 pulsations with a coherent phase structure were identified in the midlatitude magnetic field data at MSR, CAN, and ADL. A particle injection signature was not observed in the midnight sector (23.5 MLT) in the LANL data in the bottom panel. These features indicate that this auroral brightening, on which we focus in this paper, is categorized as a pseudo-breakup. A major substorm took place at 1020-1040 UT, as characterized by an auroral expansion at TIK, high-latitude magnetic field variations, midlatitude Pi 2 pulsations, and particle injection at the LANL spacecraft.

Figure 2 shows the global auroral images obtained by the far ultraviolet (FUV) Wideband Imaging Camera (WIC) on board the IMAGE satellite. This camera takes auroral images in a broadband spectral range between 140 and 160 $\mathrm{nm}$ with a temporal resolution of $120 \mathrm{~s}$ and a spatial resolution of less than $100 \mathrm{~km}$ at apogee distances. In Fig. 2, the images are plotted every 2 min from 0958:25 to 1008:38 UT in geomagnetic coordinates. The white squares indicate the footprint of the DMSP F12 spacecraft. In the images at 1002:31 and 1004:33 UT, a localized auroral brightening can be identified around 21 MLT, as indicated by the red arrow. Significant poleward expansion is not seen in the image at 1004:33 UT, and the auroral brightening disappears

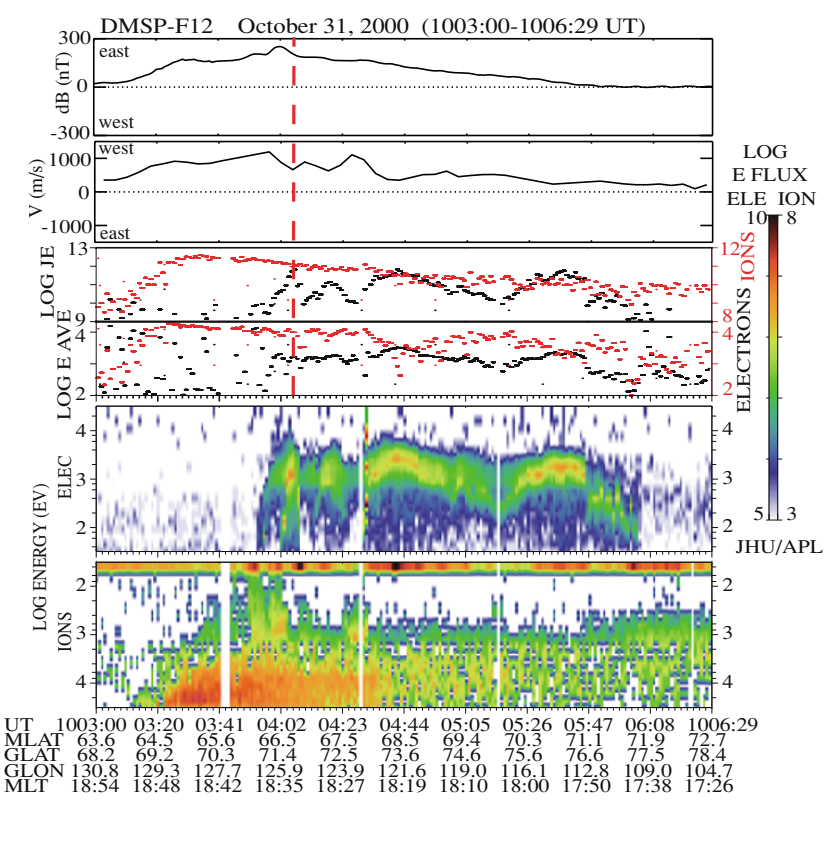

Fig. 4. Magnetic field, plasma speed, and precipitating particle data obtained by the DMSP F12 spacecraft at an altitude of $840 \mathrm{~km}$ at 1003:00-1006:29 UT on October 31, 2000. From top to bottom, magnetic field, plasma speed, electron (black) and ion (red) energy flux $\left(\mathrm{eV} / \mathrm{cm}^{2} \mathrm{~s} \mathrm{sr}\right)$, average energy $(\mathrm{eV})$, and electron and ion energy spectrograms. The red dashed line indicates the time (1004:06 UT) when the DMSP footprint crossed the brightening arc, as shown in Fig. 3.

at 1006:36 UT. The footprint of the DMSP F12 spacecraft crossed the auroral oval at $1004 \mathrm{UT}$ at $\sim 18.5$ MLT. The local time of TIK was also $\sim 18.5$ MLT at this time, which was $\sim 2.5 \mathrm{~h}$ to the duskside of the main onset region.

Figure 3 shows ground auroral images $(1000 \mathrm{~km} \times 1000$ $\mathrm{km}$ ) obtained at TIK from 1001:58 to $1004: 49$ UT. The images have been converted from the original all-sky coordinates to geographical coordinates by assuming an auroral altitude of $120 \mathrm{~km}$. Geomagnetic north (MN) is $17^{\circ}$ westward from geographic north $(\mathrm{N})$, as shown in the 1001:58 UT image. The image center is the zenith of TIK. The orange squares indicate the footprints of the DMSP F12 spacecraft at an altitude of $120 \mathrm{~km}$.

In Fig. 3, an auroral arc extends from east to west at 1003:49-1004:49 UT at a latitude of $72^{\circ} \mathrm{N}$, which is the equatorward boundary of the auroral region. The arc completely expands to the west at 1004:49 UT. The arc width is less than $1^{\circ}$ in latitude. The DMSP footprint crosses the western edge of the brightening arc from low to high latitudes at 1004:06 UT. Two auroral arcs in the NW-SE direction can be seen poleward of this brightening arc. They show continuous equatorward motion, as shown in Fig. 1.

The DMSP F12 spacecraft has a circular polar orbit and observes precipitating electrons and ions, ion drift velocities, and magnetic field variations at an altitude of $840 \mathrm{~km}$. In this study, we used 1-s time resolution data for precipitating electrons and ions and for magnetic field variations, while 4-s time resolution data were used for ion drift velocities. These data from 1003:00 to 1006:29 UT are shown in Fig. 4. As shown by the vertical red dashed line, the brightening arc corresponds to an electron inverted-V structure with a peak energy of $\sim 1 \mathrm{keV}$ at the equatorward edge 
of the electron precipitation region. The latitudinal width of the inverted-V structure is less than $1^{\circ}$, which is consistent with the observed arc width at Tixie. It is located $\sim 3^{\circ}$ (in latitude) poleward of the equatorward boundary of the ion precipitation region and $\sim 6^{\circ}$ equatorward of the poleward boundary of the electron precipitation region. The inverted-V structure is also located at the middle part of the energetic $(>1 \mathrm{keV})$ ion precipitation region. There are no Central Plasma Sheet (CPS)-type electrons equatorward of the inverted-V structures, possibly because the DMSP satellite only measures electrons in the field-aligned direction at high latitudes and may miss the CPS electrons, which have double loss-cone type pitch-angle distribution.

In the top and second panels of Fig. 4, we show magnetic field and ion drift velocities for the component perpendicular to the DMSP spacecraft's trajectory in the horizontal plane. This component can approximately be regarded as the east-west component. For the magnetic field data, eastward magnetic field intensity increases (downward fieldaligned current) from lower latitudes up to $66.5^{\circ} \mathrm{MLAT}$, and then decreases (upward field-aligned current) to $72^{\circ}$ MLAT. This feature is a typical pair of region 1 and 2 currents in the dusk sector (Iijima and Potemra, 1978). The auroral particles associated with the brightening arc (indicated by the vertical red dashed line) are located at the equatorward edge of the upward region 1 field-aligned current, with a local enhancement of the current intensity. The correspondence between the upward region 1 current and the inverted- $\mathrm{V}$ structure is consistent to that reported in previous publications (e.g., Hoffman et al., 1985; Timofeev and Galperin, 1991; Fukunishi et al., 1993).

The plasma velocity data obtained by the ion drift meter indicates that the whole region plotted in Fig. 4 corresponds to the westward (sunward in this local time) convection region. The brightening arc at $66.6^{\circ}$ MLAT is located in the middle of this sunward convection region. The arc corresponds to a local enhancement of velocity shear from west to east, which is a typical feature of auroral arcs (e.g., Burke et al., 1982).

\section{Summary and Discussion}

As suggested by Nakamura et al. (1994) and Rostoker (1998), a pseudo-substorm has the same onset characteristics as those of ordinary substorms, but they do not develop on a global scale. The important characteristics of the substorm onset are the sudden auroral brightening, highand low-latitude Pi 2 magnetic pulsations, and high-latitude negative/positive magnetic bays. As shown in Fig. 1, the auroral brightening at 1004 UT was accompanied by magnetic pulsations at low-latitude stations at MSR, CAN, and ADL. Since these pulsations at 1004 UT had coherent phase structures at the three stations, we conclude that this was a Pi 2 pulsation that occurred nearly simultaneously on a global scale. The out-of-phase characteristics of the pulsation at 1004 UT between CHD and the three low-latitude stations are also consistent with the $\mathrm{Pi} 2$ characteristics reported by Yumoto et al. (1994). The MCQ station, which was in the auroral zone in the southern hemisphere, slightly nightside of TIX, observed a small negative-H change at 1004 UT, while the TIX station observed a small positive-H change at 1004 UT. They can be recognized as small negative and positive magnetic bays associated with westward (at nightside) and eastward (at duskside) auroral electrojet currents, respectively. All of these signatures at 1004 UT were consistent with the onset signature of auroral substorm, although the electrojet currents and the auroral brightening did not develop on a global scale. From these onset signatures we identified the present event as a pseudo-substorm, which is different from a simple auroral intensification. The major onset of substorm expansion phase occurred at 1020 UT, which is $\sim 16$ min after the pseudo-substorm studied in this paper.

For the present event, several regions of inverted-V-like electrons were observed by the DMSP F12 satellite. The satellite crossed the brightening arc $1 \mathrm{~min}$ after the Pi 2 onset. The brightening arc corresponds to the most equatorward accelerated electrons, located in the middle of the energetic ion precipitation region. These facts indicate, as many previous studies have suggested (e.g., Samson et al., 1992; Dubyagin et al., 2003; Mende et al., 2003; Yago et $a l ., 2005)$, that the source region of the substorm onset is located in the inner part of the plasma sheet, which is distant from the open-closed field line boundary.

The DMSP ion drift data show that the brightening arc was located in the middle of the sunward convection region. Actually, the arc was located around the peak of the sunward convection velocity. The DMSP magnetic field data show that the arc was located at the equatorward edge of the upward region 1 field-aligned current. Shiokawa et al. (2005) have shown a similar correspondence of brightening arcs to the region 1 current in the sunward convection region, although their event is in a sequence of substorm onsets with three auroral brightenings and the corresponding three midlatitude $\mathrm{Pi} 2$ pulsations. In their event, the most equatorward arc, which brightened at the second Pi 2 pulsation, was located at the equatorward edge of the region 1 upward current. These two observations indicate that the auroral brightening at substorm onset takes place near the inner edge of the region 1 current system, as schematically shown by Fig. 6 of Shiokawa et al. (2005), and indicate that the brightening arc is probably not directly connected to the lobe reconnection. However, it is still difficult to differentiate various near-Earth substorm-onset models, i.e., flow braking (Shiokawa et al., 1998), IMF northward turning and associated convection inhomogeneity (Lyons, 1995), and near-Earth plasma sheet instability (Lui et al., 1992; Cheng and Lui, 1998; Ohtani et al., 2000). A more thorough discussion on the differentiation of the models has been given by Shiokawa et al. (2005). We should also note that DMSP was $\sim 2.5 \mathrm{~h}$ duskside of the main auroral brightening region.

Mende et al. (2003) succeeded in measuring the particle signatures around the main onset longitude. They showed that the onset of the auroral surge was produced by a superthermal electron burst, which may be created by wave acceleration, implying that the field lines in this region undergo some kind of dynamic reconfiguration. In this study, the brightening arc corresponded to inverted-V-type accelerated electrons. The superthermal electron precipitation region may be confined around the main onset longitude. 
Since our observation is $2.5 \mathrm{~h}$ duskside of the main auroral brightening region, we may miss the particle signatures at the onset longitude.

In Fig. 3, two auroral arcs are identified poleward of the brightening arc. The two arcs correspond to the two inverted-V auroral electrons at $68^{\circ}-69^{\circ}$ MLAT and 70 $71^{\circ}$ MLAT in the DMSP spectra in Fig. 4. The keogram in Fig. 1 shows that these arcs move equatorward between 1003 UT and 1014 UT. They are barely recognizable in the IMAGE FUV images, probably due to low spatial resolution or a difference between visible and FUV auroral emissions. The start of this equatorward motion seems to coincide with the Pi 2 pulsation at 1003 UT, while the end of this motion seems to coincide with the second Pi 2 pulsation at 1014 UT. It is noteworthy that the equatorwardmost arc is intensified when the equatorward-moving arc reaches the equatorward-most arc at 1014 UT in Fig. 1. The equatorward-moving arc might be produced by earthward bursty bulk flow (BBF) associated with tail reconnection in the near-Earth neutral line (Angelopoulous et al., 1994). The intensification seen when the arc reaches the brightening arc might be due to the braking of the flow (Shiokawa et al., 1998). However, the continuous equatorward motion of more than 10 min in Fig. 1 may not be consistent with the nature of the BBF, since the typical earthward velocity $(>400 \mathrm{~km} / \mathrm{s}$ ) of BBF gives a travel time of a few minutes from the near-Earth neutral line $\left(20-30 \mathrm{R}_{E}\right)$ to the inner magnetosphere $\left(<10 \mathrm{R}_{E}\right)$. The equatorward arc motion may correspond to slower Earthward flow in the plasma sheet.

Acknowledgments. The DMSP particle detectors were designed by D. A. Hardy of AFRL, and the data plots were prepared by JHU/APL. We thank D. A. Hardy and P. T. Newell for their efforts in making the DMSP particle data available. We gratefully acknowledge the Center for Space Sciences at the University of Texas at Dallas and the US Air Force for providing the DMSP thermal plasma data. The energetic particle data of LANL 1989046 was provided by D. Belian and G. Reeves of the Los Alamos National Laboratory. The IMAGE FUV data was provided by courtesy of S. B. Mende and the IMAGE FUV group at the Space Science Laboratory, University of California, Berkeley. This work was supported by a grant from the Ministry of Education, Culture, Sports, Science and Technology, Japan (Dynamics of the SunEarth-Life Interactive System, No. G-4, the 21st Century COE Program, Grant-in-Aid for Scientific Research No. 16403007, and the International STEP project). This work was also supported by the Russian Foundation for Basic Research, project no. 06-0596118, and partially by the Program of Presidium of RAS no. 16 p. 3.

\section{References}

Akasofu, S. I., The development of the auroral substorm, Planet. Space Sci., 12, 273-282, 1964.

Angelopoulos, V., et al., Statistical characteristics of bursty bulk flow events, J. Geophys. Res., 99, 21,257-21,280, 1994.

Baker, D. N., T. I. Pulkkinen, V. Angelopoulos, W. Baumjohann, and R. L. McPherron, Neutral line model of substorms: Past results and present view, J. Geophys. Res., 101, 12,975-13,010, 1996.

Burke, W. J., M. S. Gussenhoven, M. C. Kelly, D. A. Hardy, and F. J. Rich, Electric and magnetic field characteristics of discrete arcs in the polar cap, J. Geophys. Res., 87, 2431-2443, 1982.

Cheng, C. Z. and A. T. Y. Lui, Kinetic ballooning instability for substorm onset and current disruption observed by AMPTE/CCE, Geophys. Res. Lett., 25, 4091-4094, 1998.
Dubyagin, S. V., V. A. Sergeev, C. W. Carlson, S. R. Marple, T. I. Pulkkinen, and A. G. Yahnin, Evidence of near-Earth breakup location, Geophys. Res. Lett., 30, 10.1029/2002GL016569, 2003.

Fukunishi, H., Y. Takahashi, T. Nagatsuma, T. Mukai, and S. Machida, Latitudinal structures of nightside field-aligned currents and their relationships to the plasma sheet regions, J. Geophys. Res., 98(A7), 11,235$11,256,1993$.

Hoffman, R. A., M. Sugiura, and N. C. Maynard, Current carriers for the field-aligned current system, Adv. Space Res., 5, 109-126, 1985.

Iijima, T. and T. A. Potemra, Large-scale characteristics of field-aligned currents associated with substorm, J. Geophys. Res., 83, 599-615, 1978.

Lui, A. T. Y., Current disruption in the Earth's magnetosphere: Observations and models, J. Geophys. Res., 101, 13,067-13,088, 1996.

Lui, A. T. Y., R. E. Lopez, B. J. Anderson, K. Takahashi, L. J. Zanetti, R. W. McEntire, T. A. Potemra, D. M. Klumpar, E. M. Greene, and R. Strangeway, Current disruptions in the near-Earth neutral sheet region, J. Geophys. Res., 97, 1461-1480, 1992.

Lyons, L. R., A new theory for magnetospheric substorms, J. Geophys. Res., 100, 19,069-19,081, 1995.

Machida, S., Y. Miyashita, A. Ieda, A. Nishida, T. Mukai, Y. Saito, and S. Kokubun, GEOTAIL observations of flow velocity and north-south magnetic field variations in the near and mid-distant tail associated with substorm onsets, Geophys. Res. Lett., 26(6), 635-638, 1999.

Mende, S. B., C. W. Carlson, H. U. Frey, L. M. Peticolas, and N. Østgaard, FAST and IMAGE-FUV observations of a substorm onset, J. Geophys. Res., 108, 10.1029/2002JA009787, 2003.

Nakamura, R., D. N. Baker, T. Yamamoto, R. D. Belian, E. A. Bering II I, J. R. Benbrook, and J. R. Theall, Particle and field signatures during pseudobreakup and major expansion onset, J. Geophys. Res., 99, 207221, 1994.

Ohtani, S., A. T. Y. Lui, K. Takahashi, D. G. Mitchell, and T. Sarris, Ion dynamics and tail current intensification prior to dipolarization: The June 1, 1985, event, J. Geophys. Res., 105(A11), 25,233-25,246, 2000.

Olson, J. V., Pi2 pulsations and substorm onsets: A review, J. Geophys. Res., 104, 17,499-17,520, 1999.

Rostoker, G., On the place of the pseudo-breakup in a magnetospheric substorm, Geophys. Res. Lett., 25(2), 217-220, 1998.

Runov, A., et al., Current sheet structure near magnetic X-line observed by Cluster, Geophys. Res. Lett., 30(11), 1579, doi:10.1029/ 2002GL016730, 2003.

Samson, J. C., L. R. Lyons, P. T. Newell, F. Creutzberg, and B. Xu, Proton aurora and substorm intensifications, Geophys. Res. Lett., 19, 2167$2170,1992$.

Shiokawa, K., et al., Auroral observations using automatic instruments: Relations with multiple Pi 2 magnetic pulsations, J. Geomag. Geoelectr., 48, 1407-1419, 1996.

Shiokawa, K., et al., High-speed ion flow, substorm current wedge, and multiple Pi 2 pulsations, J. Geophys. Res., 103, 4491-4507, 1998.

Shiokawa, K., K. Yago, K. Yumoto, D. G. Baishev, S. I. Solovyev, F. J. Rich, and S. B. Mende, Ground and satellite observations of substorm onset arcs, J. Geophys. Res., 110, A12225, doi:10.1029/2005JA011281, 2005.

Solovyev, S. I., D. G. Baishev, E. S. Barkova, N. E. Molochushkin, and K. Yumoto, Pi 2 magnetic pulsations as response on spatio-temporal oscillations of auroral arc current system, Geophys. Res. Lett., 27, 1839$1842,2000$.

Timofeev, E. and Y. Galperin, Convection and currents in stable auroral arcs and inverted V's, J. Geomagn. Geoelectr., 43, 259-274, 1991.

Yago, K., K. Shiokawa, K. Hayashi, and K. Yumoto, Auroral particles associated with a substorm brightening arc, Geophys. Res. Lett., 32, L06104, doi:10.1029/2004GL021894, 2005.

Yumoto, K., H. Osaki, K. Fukao, K. Shiokawa, Y. Tanaka, S. I. Solovyev, G. Krymskij, E. F. Vershinin, V. F. Osinin, and 210 (deg) MM magnetic observation group, Correlation of high- and low-latitude Pi 2 magnetic pulsations observed at $210(\mathrm{deg})$ magnetic meridian chain stations, $J$. Geomag. Geoelectr., 46, 925-935, 1994.

Yumoto, K. and the CPMN group, Characteristics of Pi 2 magnetic pulsations observed at the CPMN stations: A review of the STEP results, Earth Planets Space, 53, 981-992, 2001.

K. Yago, K. Shiokawa (e-mail: shiokawa@stelab.nagoya-u.ac.jp), K. Yumoto, D. G. Baishev, S. I. Solovyev, and F. J. Rich 